\title{
High-temperature oxidation of heat-resistant alloys with small amounts of sulfur and reactive elements $(\mathrm{Y}, \mathrm{Hf})$ for $1800 \mathrm{ks}$ at $1373 \mathrm{~K}$
}

\section{微量の硫黄および活性元素(Y,Hf)を添加した耐熱合金の $1373 K$ における $1800 \mathrm{ks}$ 間酸化}

\author{
Tadaaki AMANO, Takahiro OZAWA, Keiko KUDO, Norihiro MATSUMOTO, Naoki SAKAl and Hisao ISOBE \\ Department of materials science and ceramic technology, Shonan Institute of Technology, 1-1-25, \\ Tsujido-Nishikaigan, Fujisawa, Kanagawa, 251-8511 JAPAN \\ TEL:81-466-30-0225,FAX:81-466-36-1594,E-mail:amano@mate.shonan-it.ac.jp \\ ( Received 6, November 2000 Accepted 9, June 2001)
}

High-temperature oxidation of heat-resistant alloys with small amounts of sulfur and reactive elements (Y, Hf) was studied for $1800 \mathrm{ks}$ in air at $1373 \mathrm{~K}$. The mass changes of the $2,53,104$ and $171 \mathrm{ppmS}$ were $0.5 \sim 0.9 \times$ $10^{-2} \mathrm{~kg} / \mathrm{m}^{2}$. On the other hand, the mass changes of the $5,185,491$ and $1300 \mathrm{ppmS}$ were less than $0.2 \times 10^{-2} \mathrm{~kg} / \mathrm{m}^{2}$ or negative values because of marked spalling of oxide scale on the alloys. Oxide on the 1300ppmS was convoluted, and those on the alloys with reactive elements were planar morphology. The formation of planar morphology on the oxide and that of stable reactive elements sulfide particles may lead to good oxide adherence.

Keywords: Fe-20Cr-4Al, Sulfur, High-temperature oxidation, Oxide adherence, Yttrium, Hafnium

\section{INTRODUCTION}

耐熟合金は合金表面に緻密な酸化皮膜を形成するこ とにより高温耐酸化性を示す。しかしながら、その酸化 皮膜は冷却過程でしばしば剥離する。酸化皮膜の剥離は 酸化皮膜／合金界面に偏析する硫黄の影響であるとも 言われている。1,2著者らはすでにアルミナ形成耐熱合 金について、360ks 間までの高温酸化実験を行ってきた が、 ${ }^{3}$ 実用的な観点からすればさらなる長時間の酸化 実験が求められる。

本研究では、微量の硫黄並びに微量の硫黄および活性 元素 (Y、Hf) を添加した $\mathrm{Fe}-20 \mathrm{Cr}-4 \mathrm{Al}$ 合金の乾燥空気 中、1373K で $1800 \mathrm{ks}$ 間の高温酸化実験を行い、合金上 に生成するアルミナ皮膜の密着性について検討した。

\section{EXPERIMENTAL}

$\mathrm{Fe}-20 \mathrm{Cr}-4 \mathrm{Al}$ (2、5、7、53、104、171、185、491 および $1300 \mathrm{ppmS}$ ) 合金、185ppmS 合金に微量の Y お よび Hf を添加した Fe-20Cr-4Al（10、300 および $3700 \mathrm{ppmY})$ 合金および Fe-20Cr-4Al (500、900、1900 および 4300ppmHf) 合金をアーク溶解法により溶製し、 その後熱間・冷間圧延により約 $0.5 \mathrm{~mm}$ の厚さにした。 次いで、切断により約 $10 \mathrm{~mm} \times 20 \mathrm{~mm}$ の板状試片を作 製した。これらの合金について $1473 \mathrm{~K}$ で $18.0 \mathrm{ks}$ 間の真 空焼鈍を行い、ダイヤモンドペーストを用いて合金表面 を鏡面仕上げし、アルコール中で超音波洗浄後、供試材 とした。酸化は $1373 \mathrm{~K} て ゙ ~ 1800 \mathrm{ks}$ 間、乾燥空気中で行 つた。酸化後の試料について、質量変化量を測定し、次
いで外観を観察した。その後、酸化皮膜の結晶相をX 線回折装置を用いて明らかにした。酸化皮膜の形態およ び下地合金表面の形態を SEM (Scanning Electron Microscope) を用いて観察した。酸化皮膜／合金界面の 組成については EPMA (Electron Probe X-ray Microanalyzer) を用いて明らかにした。

\section{RESULTS}

Figure 1 に各合金の質量変化量を示す。2ppmS の質 量変化量は $0.8 \times 10^{-2} \mathrm{~kg} / \mathrm{m}^{2}$ の値を示した。しかしなが ら、 $5 \mathrm{ppmS}$ の質量変化量は $0.2 \times 10^{-2} \mathrm{~kg} / \mathrm{m}^{2}$ の值を示し、 $2 \mathrm{ppmS}$ のそれより著しく小さく、このことは酸化皮膜 の剥離に帰される。その後、53ppmS まで質量変化量は 硫黄含有量の増加とともに増加したが、104ppm S から 减少した。491 および $1300 \mathrm{ppmS}$ では質量変化量は負 の値を示した。この結果は酸化皮膜の著しい剥離を示唆 している。300 および $3700 \mathrm{ppmY}$ の質量変化量は 0.9 〜 $1.1 \times 10^{-2} \mathrm{~kg} / \mathrm{m}^{2}$ の值を、またHf添加合金の質量変 化 量は $0.7 \sim 1.2 \times 10^{-2} \mathrm{~kg} / \mathrm{m}^{2}$ の值を示した。

Figure 2 に各合金の酸化後の外観を示す。2ppmS で は酸化皮膜の剥離はわずかであったが、 5 および $7 \mathrm{ppmS}$ では、酸化皮膜の著しい剥離が認められ、53 および $104 \mathrm{ppmS}$ では酸化皮膜の残留領域が認められたものの、 491 および 1300ppmS では表面全体から剥離した。300、 $3700 \mathrm{ppmY}$ および Hf 添加合金では酸化皮膜の剥離法 観祭されなかった。X線回折の結果より、合金表面に生 成した酸化皮膜は全ての合金で $\alpha-\mathrm{Al}_{2} \mathrm{O}_{3}$ が支配的であ 


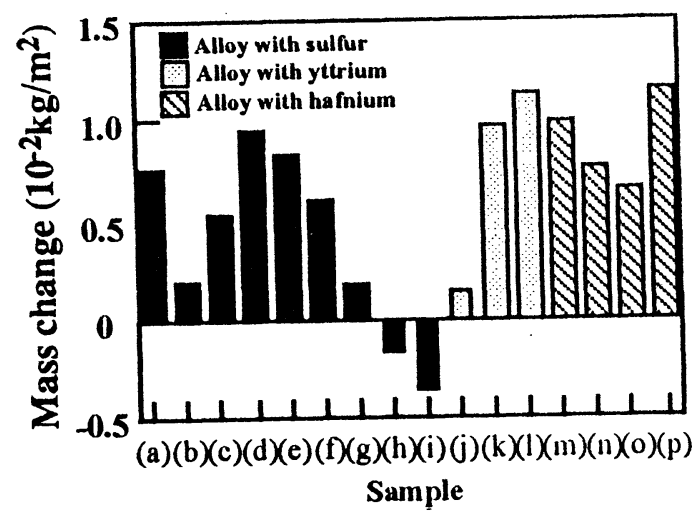

Fig. 1. Mass change of $\mathrm{Fe}-20 \mathrm{Cr}-4 \mathrm{Al}$ alloys with small amounts of sulfur and reactive elements exposed for $1800 \mathrm{ks}$ in air at $1373 \mathrm{~K}$. (a) $2 \mathrm{ppmS}$. (b) $5 \mathrm{ppmS}$. (c) $7 \mathrm{ppmS}$. (d) $53 \mathrm{ppmS}$. (e) $104 \mathrm{ppmS}$. (f) $171 \mathrm{ppmS}$. (g) $185 \mathrm{ppmS}$. (h) $491 \mathrm{ppmS}$. (i) $1300 \mathrm{ppmS}$. (j) $10 \mathrm{ppmY}$. (k) 300ppmY. (l) 3700ppmY. (m) 500ppmHf (n) 900ppmHf. (o) 1900ppmHf. (p) 4300ppmHf.
(a)
(b)
(c) (d)
(e) (f)
(g) (h) (i)
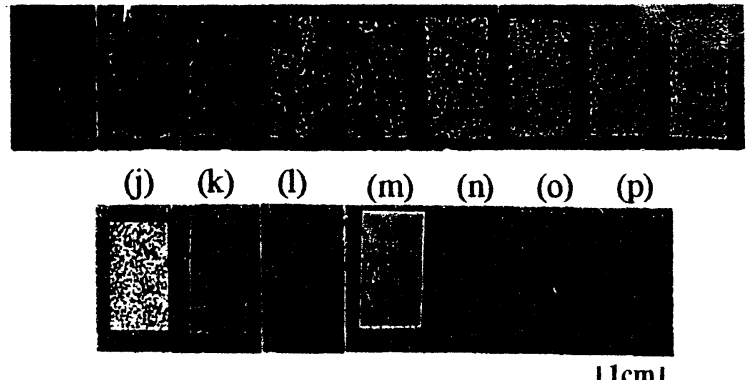

$1 \mathrm{~cm}$

Fig. 2. Surface appearance of $\mathrm{Fe}-20 \mathrm{Cr}-4 \mathrm{Al}$ alloys with small amounts of sulfur and reactive elements exposed for $1800 \mathrm{ks}$ in air at $1373 \mathrm{~K}$. (a) $2 \mathrm{ppmS}$. (b) $5 \mathrm{ppmS}$.

(c) 7ppmS. (d) 53ppmS. (e) 104ppmS. (f) $171 \mathrm{ppmS}$.

(g) $185 \mathrm{ppmS}$. (h) $491 \mathrm{ppmS}$. (i) 1300ppmS. (j) 10ppmY.

(k) $300 \mathrm{ppmY}$. (l) $3700 \mathrm{ppmY}$. (m) $500 \mathrm{ppmHf}$.

(n) 900 ppmHf. (o) 1900 ppmHf. (p) 4300ppmHf.

り、300 および3700ppmY で $\mathrm{Y}_{3} \mathrm{Al}_{5} \mathrm{O}_{12}$ 、そして全ての $\mathrm{Hf}$ 添加合金で $\mathrm{HFO}_{2}$ が検出された。

Figure 3 に各合金上に生成した酸化皮膜の表面形態 を示す。2ppmS の酸化皮膜表面は平滑であったが、 硫黄含有量の增加とともに大きな起伏を生じた。一方、 $3700 \mathrm{ppmY}$ および 4300ppmHf の酸化皮膜表面は平 滑な形態を示した。

EPMAにより 1300ppmS の酸化後の合金断面を分析 すると合金中に $3 \mu \mathrm{m}$ 、酸化皮膜-合金界面に $6 \mu \mathrm{m}$ 程度 の $\mathrm{Cr}$ 硫化物粒子が観察された。この粗大な $\mathrm{Cr}$ 硫化物粒 子の生成が酸化皮膜の剥離に影響をおよぼすものと考え られる。
Figure 4 に3700ppmY の酸化後の合金断面における 形態およびX 線像を示す。合金中に多くのY硫化物粒子 が存在した。Y は硫黄と安定なY硫化物粒子を生成し、 硫黄を合金中にとどめる。その結果、酸化皮膜の密着性 を改善するものと考えられる。

(a)

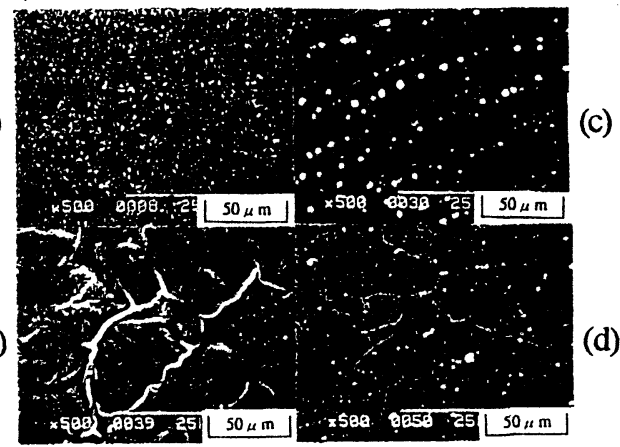

Fig. 3. Scanning electron micrographs of oxide scales on Fe-20Cr-4Al alloys with small amounts of sulfur and reactive elements exposed in air for $1800 \mathrm{ks}$ at $1373 \mathrm{~K}$.

(a) $2 \mathrm{ppmS}$. (b) $1300 \mathrm{ppmS}$. (c) $3700 \mathrm{ppmY}$

(d) 4300ppmHf.

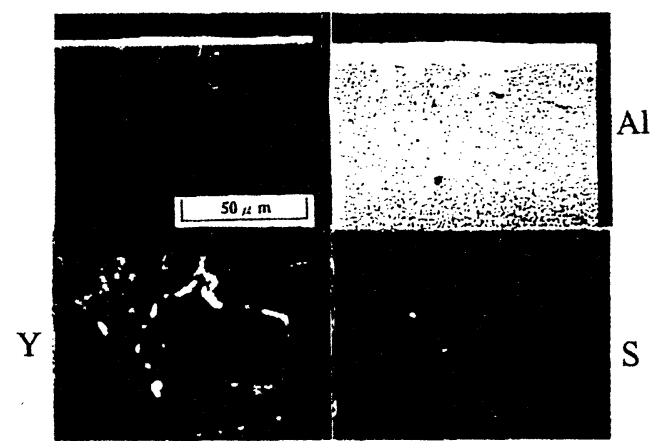

Fig. 4. Microstructure and $\mathrm{X}$-ray images of crossscection of $3700 \mathrm{ppmY}$ alloy exposed for $1800 \mathrm{ks}$ in air at 1373K.

\section{N. CONCLUSION}

硫黄含有合金においては硫黄の添加量の変化により 酸化皮膜の密着性が左右され、また活性元素添加合金に おいては活性元素の適量添加により酸化皮膜の密着性 は向上することが分かった。

\section{REFERENCES}

${ }^{1} \mathrm{~T}$. Amano, T. Watanabe and K. Michiyama, J.Japan Inst. Metals, 61, 1077 (1997).

${ }^{2}$ T. Amano, T. Watanabe and K. Michiyama, Oxid. Met., 53, 451 (2000).

${ }^{3}$ T. Amano, A. Hara, N. Sakai and K. Sasaki, Mat. High Temp., 17, 117 (2000).

Presented at '00 SAS Intelligent Symposium 